\title{
Expression of the Functional Cone Phototransduction Cascade in Retinoblastoma
}

Richard L. Hurwitz,"* Emil Bogenmann," Ramon L. Font," Vien Holcombe," and Dorothy Clark*

*Division of Hematology-Oncology, Department of Pediatrics, ${ }^{\ddagger}$ Department of Cell Biology, and Department of Ophthalmology, Baylor College of Medicine, Houston, Texas 77030; and "Division of Hematology-Oncology, Children's Hospital of Los Angeles,

Los Angeles, California 90027

\begin{abstract}
Retinoblastoma is a malignant intraocular tumor that primarily affects small children. These tumors are primitive neuroectodermal malignancies, however some of them show morphologic evidence of differentiation into photoreceptors. Phototransduction cascades are a series of biochemical reactions that convert a photon of light into a neural impulse in rods and cones. The components of these cascades are uniquely expressed in photoreceptors and, although functionally similar, distinct components of these cascades are expressed in rods and cones. Using HPLC anion exchange chromatography, Western blot analysis, and specific monoclonal and polyclonal antibodies, we found that the cone but not the rod cGMP phosphodiesterase is functionally expressed in all six primary retinoblastomas examined and in three continuous retinoblastoma cell lines. Morphologic evidence of differentiation did not correlate with the expression of the enzyme. Furthermore, GTP analogues could activate the phosphodiesterase activity suggesting that an intact phototransduction cascade is present in the tumors. The presence of the cone phototransduction cascade in retinoblastoma confirms that this tumor has biochemically differentiated along the cone cell lineage. (J. Clin. Invest. 1990. 85:1872-1878.) cGMP cascade • phosphodiesterase $\bullet$ photoreceptor $\bullet$ G-protein $\bullet$ vision
\end{abstract}

\section{Introduction}

Retinoblastoma is an intraocular tumor that primarily affects small children (1) and has been found to exist in both inherited and sporadic forms. The inherited form is autosomal dominant, is usually presented bilaterally, and has been correlated with an alteration on the long arm of the 13th chromosome (2, 3 ). Genetic abnormalities have been associated with both forms (4-7) and a gene in the retinoblastoma locus has been cloned (8).

Light activates a photoreceptor photopigment and initiates a biochemical cascade which results in the hyperpolarization of the photoreceptor membrane (9). Some of the various components of the phototransduction cascades have recently been isolated and similar but not identical proteins have been found in rods and cones. Rhodopsin is the light receptor in rods (10)

Address reprint requests to Richard L. Hurwitz, M.D., One Baylor Plaza, Department of Pediatrics, Baylor College of Medicine, Houston, TX 77030

Received for publication 10 October 1989 and in revised form 19 December 1989.

J. Clin. Invest.

(c) The American Society for Clinical Investigation, Inc.

0021-9738/90/06/1872/07 \$2.00

Volume 85, June 1990, 1872-1878 while the blue, red, and green photopigments are the light receptors in cones $(11,12)$. These receptors, when activated by a photon of light, allow a GTP-GDP exchange to occur on rod and cone GTP-binding proteins (transducins) (13). GTPtransducin in turn can activate a rod or cone cGMP phosphodiesterase that results in the rapid hydrolysis of cGMP to GMP $(14,15)$. The decreased level of cGMP directly closes a cGMP-gated cation channel in both rods and cones and results in the hyperpolarization of the cell (16-21).

The cone phosphodiesterase is separable from the rod phosphodiesterase using anion exchange $\operatorname{HPLC}(15,22)$ and has recently been purified to homogeneity (23). Monoclonal antibodies prepared to the photoreceptor phosphodiesterases have demonstrated the existence of both common and unique epitopes on the cone and rod isoforms $(15,24)$. These antibodies were used to immunocytochemically localize these enzymes in cones and rods $(15,24)$. The cone enzyme is probably a homodimer with an apparent subunit molecular mass of 92 $\mathrm{kD}(15,22-24)$. The rod enzyme contains two apparent subunits of 88 and $84 \mathrm{kD}$, respectively (14). Both isozymes are associated with low molecular mass inhibitory subunits (14, 23, 25).

The mRNAs for the red and green photopigments and the cone transducin but not for their rod counterparts have been detected in retinoblastoma cell lines (26). The demonstration of functional expression in retinoblastoma of one or more components of the cone-specific cascade would further confirm that the tumor evolved along the cone cell lineage. Portions of six retinoblastomas as well as several tumor-derived cell lines have been examined and have been found to express enzymatically active cone but not rod phosphodiesterase. This phosphodiesterase can be activated by an endogenous GTPbinding protein indicating that a functional phototransduction cascade related to that found in normal cones is expressed in these tumors.

\section{Methods}

Retinoblastomas were obtained from patients undergoing enucleation for the diagnosis and treatment of their disease at Texas Children's Hospital, Houston, TX. The tumors were protected from light using aluminum foil and stored frozen in liquid nitrogen. Human retinas from cadavers were obtained from the Lion's Eye Bank (Houston, TX). Bovine retinas were obtained frozen from Hormel (Omaha, NE). ROS-1, a monoclonal antibody that specifically recognizes the rod and cone phosphodiesterases $(15,24)$, and ACC, a monoclonal antibody that specifically recognizes calmodulin $(\mathrm{CaM})^{1}(27)$, were gifts from Dr. Joe Beavo, University of Washington. CaM isolated as the protein product of a chicken CaM cDNA expressed in a bacterial system (28) was a gift from Dr. Anthony Means, Baylor College of Medicine. Cell lines were grown in the dark as previously described (29).

1. Abbreviation used in this paper: CaM, calmodulin. 
All subsequent operations were undertaken using room light. Samples were prepared for and run on anion exchange HPLC by a modification of a method previously described (15). Each tissue sample $(0.10-0.25 \mathrm{~g})$ was homogenized in $1 \mathrm{ml} 10 \mathrm{mM}$ Tris/HCl, $\mathrm{pH} \mathrm{7.5,1}$ mM DTT, $200 \mu \mathrm{M}$ PMSF and centrifuged in a microfuge for $10 \mathrm{~min}$, and then twice for $10 \mathrm{~min}$ each in an airfuge (Beckman Instruments, Inc., Palo Alto, CA) at $100,000 \mathrm{~g}$. Samples were injected onto a Mono Q (Pharmacia Fine Chemicals, Piscataway, NJ) anion exchange HPLC column and the protein eluted at a rate of $0.5 \mathrm{ml} / \mathrm{min}$ with the homogenization buffer plus a $0.05-0.5 \mathrm{M} \mathrm{NaCl}$ linear gradient. The run time was $60 \mathrm{~min}$ and samples were collected at 30 -s intervals.

Immunoadsorptions and phosphodiesterase assays were performed in room light as previously described $(24,27) .100 \mu \mathrm{l}$ rabbit antimouse $\operatorname{IgG}_{1}$ (Miles Laboratories Inc., Naperville, IL) and $100 \mu \mathrm{l}$ of ascites fluid containing the monoclonal antibody ROS-1 (at least 1 $\mathrm{mg} / \mathrm{ml}$ ) were sequentially coupled to $1-\mathrm{ml}$ formalin-fixed Staphylococcus aureus. The antibody-coupled cells were washed by centrifugation. The monoclonal antibody ACC was coupled directly to Staphylococcus aureus. $25 \mu \mathrm{l}$ of these cells were incubated with the fractions containing phosphodiesterase in a total volume of $100 \mu \mathrm{l}$ for $2 \mathrm{~h}$. The samples were centrifuged in a microfuge (Fisher Scientific Co., Pittsburgh, PA) for 2 min and the supernatants assayed for phosphodiesterase activity at $30^{\circ} \mathrm{C}$ for $5 \mathrm{~min}$ using $10 \mu \mathrm{M}\left[{ }^{3} \mathrm{H}\right] \mathrm{CGMP}(15 \mathrm{Ci} / \mathrm{mmol}$; ICN Biomedicals Inc., Irvine, $\mathrm{CA}$ ) as the substrate. Samples were assayed using $2 \mathrm{mg}$ histone H3 (Sigma Chemical Co., St. Louis, MO) per milliliter as an activator of the photoreceptor phosphodiesterases (22, 30, 31), 1 mM EGTA (Sigma Chemical Co.), or $500 \mu \mathrm{M} \mathrm{CaCl}_{2}$ (Sigma Chemical Co.), and $100 \mathrm{nM}$ CaM. The product of the reaction was converted to guanosine by incubation with $5 \mu \mathrm{g}$ Crotalus atrox venom (Sigma Chemical Co.) for $15 \mathrm{~min}$. The reaction mixture was passed through a DEAE Sephadex (Pharmacia Fine Chemicals) column. The nucleoside was collected in the void volume, Ecolume scintillation cocktail (ICN Biomedicals Inc.) was added, and the samples were counted in a scintillation counter (LKB Instruments Inc., Bromma, Sweden). The efficiency of recovery of the nucleoside was monitored in two ways. First, an excess of purified phosphodiesterase was allowed to hydrolyze all of the cyclic nucleotide in the assay. The assay was completed as described above and the results expressed as a percentage of the total $\mathrm{cpm}$ in the assay. If the results were $<90 \%$ recovery of the nucleoside, the assay was repeated. The recovery of nucleoside from each column was monitored by eluting the columns with $0.5 \mathrm{M} \mathrm{NaCl}$ and counting the samples on the scintillation counter as described above. If these results when added to the results of the assay indicated $<90 \%$ recovery of nucleoside, the assays were repeated.

The rod and cone outer segment phosphodiesterases and $61 \mathrm{kD}$ CaM-dependent phosphodiesterase were initially purified as previously described $(24,32)$. The rod and cone outer segment phosphodiesterases were further purified by anion exchange HPLC using a Mono Q (Pharmacia Fine Chemicals) column as described above. The CaM-dependent phosphodiesterase was further purified by anion exchange HPLC using a TSK DEAE 5PW (Toya Soda) column using the same $\mathrm{NaCl}$ gradient and buffers as the rod outer segment enzyme.

The tumor was prepared for Western blot analysis by homogenizing in $1 \mathrm{ml} 10 \mathrm{mM}$ Tris/ $\mathrm{HCl}, \mathrm{pH} 7.5,1 \mathrm{mM}$ DTT, $150 \mathrm{mM} \mathrm{NaCl}, 200$ $\mu \mathrm{M}$ PMSF, and $1 \%$ Triton X-100 and centrifuging as described previously (24). Half of the resulting extract was applied to ethanolamine-blocked CNBr-activated agarose and the other half to ROS-1 coupled to $\mathrm{CNBr}$-activated agarose prepared as previously described (15). The samples were incubated at $4^{\circ} \mathrm{C}$ for $2 \mathrm{~h}$ on a rotator, washed twice in $10 \mathrm{mM}$ Tris/ $\mathrm{HCl}, \mathrm{pH} 7.5,150 \mathrm{mM} \mathrm{NaCl}$ and once in $10 \mathrm{mM}$ Tris/ $\mathrm{HCl}, \mathrm{pH} 7.5$, in a microfuge, and then eluted with $8 \mathrm{M}$ urea. Samples were electrophoresed in SDS on a $15 \%$ total acrylamide, $0.08 \%$ bisacrylamide gel as previously described $(14,15)$. The gel was blotted onto nitrocellulose at $30 \mathrm{~V}$ for $6 \mathrm{~h}$, blocked with $3 \%$ casein and probed with a monospecific antisera (Dr. Richard Lolley, Veterans Administration Hospital, Sepulveda, CA) directed to the bovine rod phosphodiesterase (33). The signal was developed using a Protoblot kit
(Promega Biotec, Madison, WI) as specified in the manufacturer's instructions.

\section{Results}

The results of a typical anion exchange HPLC cGMP phosphodiesterase profile using a normal human retina are depicted in Fig. $1 \mathrm{~A}$. Enzyme assays were performed in the presence or absence of histone, a protein that has been shown to activate both rod and cone phosphodiesterases $(22,30,31)$. At least four heterogeneous peaks of cGMP phosphodiesterase activity that could be activated by histone were found in agreement with previously described results (15). Investigations have previously established that the first peak of activity (fractions $39-42 ; 18 \%$ of the total activity in the profile shown in Fig. $1 \mathrm{~A}$ ) was derived from cones while the activity observed in the latter fractions (52-62; $68 \%$ of the activity) was derived from rods $(15,22,24)$. The remaining activity can be immunoadsorbed by an antibody to $\mathrm{CaM}$, can be activated in the presence of calcium and CaM, and appears to have characteristics similar to the CaM-dependent phosphodiesterases derived from brain (27). The enzyme HPLC profiles were highly reproducible and no other tissue has been found to contain the photoreceptor-derived isozymes (30). Similar activities observed in tumors would therefore be suspected of being of photoreceptor origin.

Retinoblastomas were obtained from patients who were undergoing diagnostic and therapeutic enucleation. The tissue was grossly and histologically determined to be free of normal retina. The tissue was subjected to the same examination of phosphodiesterase activity as described above. In this profile (Fig. $1 B$ ), a prominent peak of histone-stimulated cGMP phosphodiesterase activity was found in the same fractions as the cone phosphodiesterase from a normal human retina. No activity was found in the fractions in which the rod enzyme would have been expected (fractions 52-62).

To verify that this histone-stimulated phosphodiesterase activity was derived from photoreceptors, the rod and cone phosphodiesterase antibody $(\operatorname{ROS}-1)(15,22,24)$ was used to immunotitrate the enzyme activity (Fig. $1 C$ ). The antibody reacted with $86 \%$ of the activity found in the profile. A monoclonal antibody (ACC) (27) to CaM immunoadsorbed the remaining phosphodiesterase activity in the presence of $100 \mathrm{nM}$ $\mathrm{CaM}$ and $0.5 \mathrm{mM} \mathrm{CaCl}_{2}$ (Fig. $1 \mathrm{D}$ ) suggesting that $14 \%$ of the activity can be accounted for by CaM-dependent phosphodiesterases. These activities could be stimulated by either histone or CaM (Fig. $1 E$ ). This finding suggested that a CaM-dependent, histone activatable phosphodiesterase eluted in similar fractions as the photoreceptor enzyme on the HPLC profile. Three CaM-dependent phosphodiesterase isozymes have previously been shown to be separated by TSK-DEAE HPLC anion exchange chromatography (34). When an extract from bovine brain was applied to the Mono $Q$ column and eluted with an identical gradient, the two CaM-dependent isozymes present in this tissue were found in fractions 38-41 and 43-46. There are no ROS- 1 immunoadsorbed phosphodiesterase isozymes in brain. Furthermore, when purified bovine brain $61 \mathrm{kD}$ CaM-dependent phosphodiesterase was assayed in the presence of increasing concentrations of histone and compared to the activity from purified rod outer segment phosphodiesterase also assayed in the presence of histone, a 


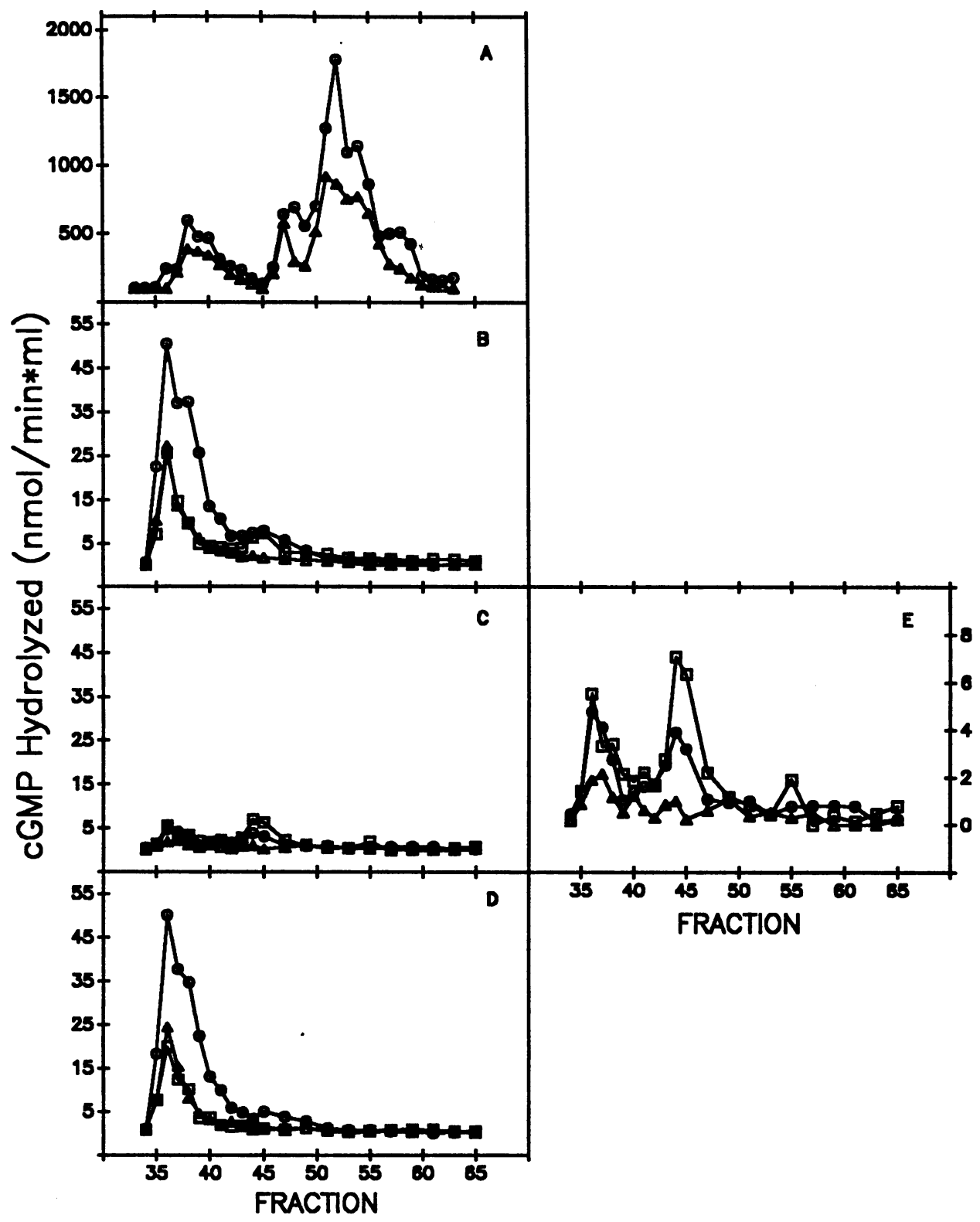

Figure 1. Comparative analysis of human retina and retinoblastoma cGMP phosphodiesterase activities using HPLC and specific monoclonal antibodies. $(A)$ HPLC profile of normal human retina assayed in the presence of histone $(2 \mathrm{mg} / \mathrm{ml})(0)$ or EGTA $(1 \mathrm{mM})(\Delta)$. (B) HPLC profile of retinoblastoma tumor incubated with Staphylococcal aureus alone and similarly assayed in the presence of histone (0), EGTA ( $\Delta$ ), or calcium $(500 \mu \mathrm{M})$ and $\mathrm{CaM}(100$ $\mathrm{nM})(\square)$. (C) Fractions from the HPLC profile in $B$ were immunoadsorbed with Staphylococcal aureus coupled to ROS-1, a monoclonal antibody that specifically recognizes the photoreceptor phosphodiesterases $(15,24)$, and assayed as in $B$. (D) Fractions from the HPLC profile in $B$ were immunoadsorbed with Staphylococcus aureus coupled to ACC, a monoclonal antibody that specifically recognizes $\mathrm{CaM}$ and $\mathrm{CaM}$ bound to the calmodulindependent phosphodiesterases (27), and assayed as in $B$. $(E)$ The profile in $C$ with an expanded scale.

similar activation curve was demonstrated for both enzymes (Fig. 2). Since proteolysis has already been demonstrated to activate both isozymes $(25,35)$, immunotitration and anion exchange HPLC analysis must be used concurrently to verify the presence of the cone photoreceptor isozyme.

To verify that the phosphodiesterase was the cone isozyme, the subunit molecular mass of the ROS- 1 immunoadsorbed cGMP phosphodiesterase was examined using Western blot analysis with a monospecific polyclonal antisera (33) to the photoreceptor phosphodiesterase. Extracts were prepared from a detergent-solubilized retinoblastoma and immunoadsorbed with ROS-1 coupled to agarose or with agarose alone. The eluted protein from the agarose was subjected to Western blot analysis using the antisera as a specific probe (Fig. 3). Bovine cone and rod phosphodiesterase enzymes served as controls. The antisera reacted with the immunopurified cone as well as the rod isozymes. This was an expected result since both the rod and cone isoforms share a common epitope recognized by
ROS-1. Greater than 95\% of the histone-stimulated cGMP phosphodiesterase activity was removed from the retinoblastoma extract by ROS- 1 . In the lane containing the ROS- 1 immunoadsorbed extract, a single polypeptide of $\sim 92 \mathrm{kD}$ that appeared to comigrate with the bovine cone phosphodiesterase and which was distinct from the bovine rod isozyme was observed. No labeled polypeptides were observed in the lane containing the agarose adsorbed extract indicating that the immunoadsorption was specific. Therefore, the cone and not the rod phosphodiesterase protein was present in the primary retinoblastomas.

Using the HPLC analysis and antibody immunoadsorption techniques described above, the cone but not the rod phosphodiesterase has been found in all six retinoblastomas so far examined. The CaM-dependent phosphodiesterase was also present in varying amounts in these tumors. The results of these experiments are summarized in Table $I$.

Five continuous cell lines derived from retinoblastomas 


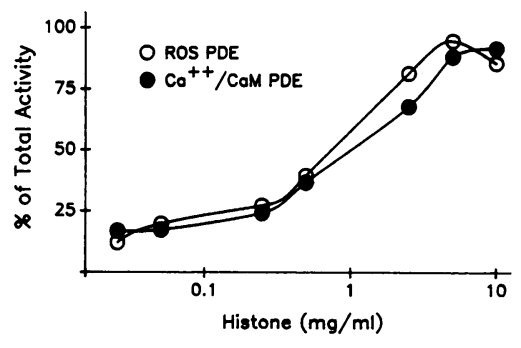

Figure 2. Activation of photoreceptor and calmodulin-dependent phosphodiesterases by histone. Purified photoreceptor phosphodiesterase (o) and calmodulin-dependent phosphodiesterase (๑) were assayed in the presence of EGTA $(1 \mathrm{mM})$ and the indicated concentrations of histone (H3) using $10 \mu \mathrm{M}\left[{ }^{3} \mathrm{H}\right] \mathrm{CGMP}$ as substrate. Total activity was defined as the activity assayed after trypsin proteolysis for the photoreceptor phosphodiesterase and in the presence of calcium and calmodulin for the calmodulin-dependent phosphodiesterase.

(26) have been examined for cGMP phosphodiesterase activity using the HPLC methodology and enzyme activity assays described above. The results of these experiments are also summarized in Table I. The cone phosphodiesterase was found in three of these cultures. The CaM-dependent phosphodiesterase was also found in varying amounts in these cultures. The phosphodiesterases were found to be present but with approximately one to two orders of magnitude less specific activity than found in the primary tumors.

The presence of the cone transducin and red-green pigment mRNA but not the rod transducin or rhodopsin mRNA has been previously demonstrated in seven retinoblastoma cell lines (26). To demonstrate the presence of the functional phototransduction cascade in the cell line, the nonhydrolyzable GTP analogue 5'guanylylimidodiphosphate (GppNHp) was added to a homogenate prepared from the RBLA22 cell line and the homogenate was assayed for CGMP phosphodiesterase activity (Table II). A significant elevation of activity was demonstrated in the presence of GppNHp suggesting that the cone transducin is functionally expressed and can interact with the cone phosphodiesterase in a GTP-dependent manner. The presence of calcium/CaM also produced an increase in activity as would be predicted from the immunotitration analysis of the HPLC profile for this cell line (Table I). Similar results have been obtained using the RBLA12 and RBLA28 cell lines as well as with a sample of fresh tumor. When purified activated $\mathrm{G}_{\mathrm{s}} \alpha, \mathrm{G}_{\mathrm{i}} \alpha, \mathrm{G}_{\mathrm{o}} \alpha$, or $\mathrm{G}_{\mathrm{k}} \alpha$ (provided by Dr. Lutz Birnbaumer, Baylor College of Medicine) was added to purified rod outer segment phosphodiesterase either in the presence or absence of urea-treated outer segment membranes (36), no activation of phosphodiesterase activity was found. As expected, activation of the phosphodiesterase did occur in the presence of urea treated outer segment membranes and purified rod transducin $\left(T_{R \alpha}\right)$. Therefore, the activation of the phosphodiesterase activity observed in the retinoblastoma cell lines implies that the cone transducin and not another GTP binding protein is responsible for the activation of the cone phosphodiesterase activity. These results strongly suggest that the members of the cone phototransduction cascade, whose mRNAs have previously been shown to be present (26), are expressed in a functional form.

\section{Discussion}

Phototransduction, the mechanism that converts an adsorbed photon of light into a neural impulse, is a series of biochemical

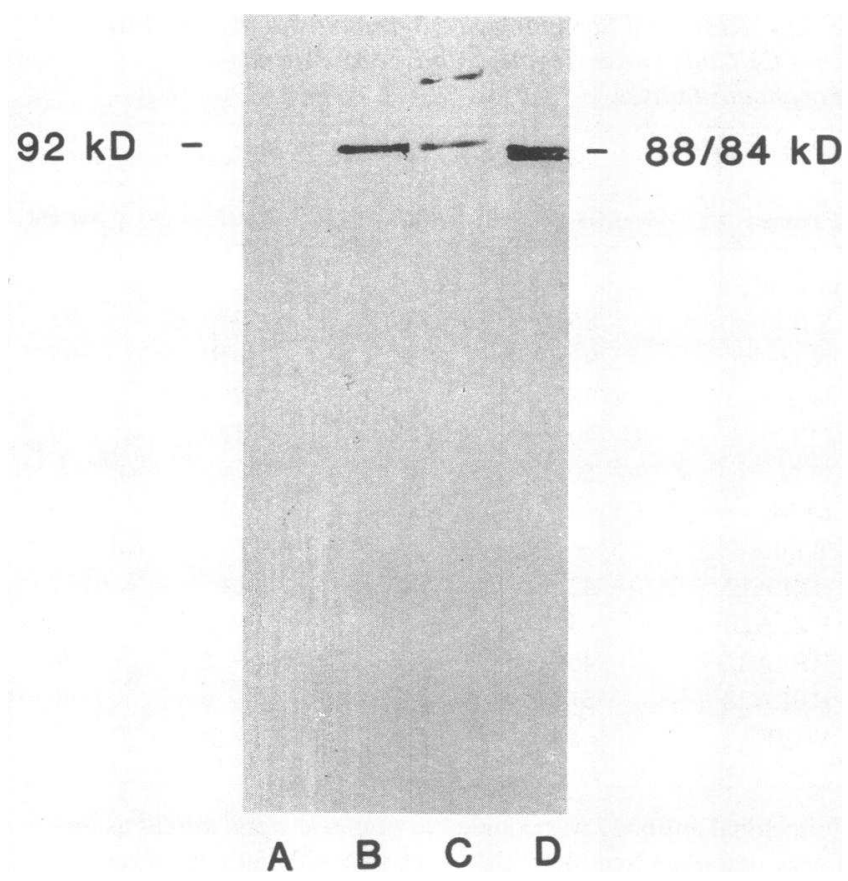

Figure 3. Western blot analysis of the photoreceptor phosphodiesterase in retinoblastoma. The tumor was prepared for Western blot analysis by homogenizing in $1 \mathrm{ml} 10 \mathrm{mM}$ Tris/ $\mathrm{HCl}, \mathrm{pH} 7.5,1 \mathrm{mM}$ DTT, $150 \mathrm{mM} \mathrm{NaCl}, 200 \mu \mathrm{M}$ PMSF, and $1 \%$ Triton X-100 and centrifuging as described previously (24). Half of the resulting extract was applied to ethanolamine-blocked $\mathrm{CNBr}$-activated agarose and the other half to ROS- 1 coupled to CNBr-activated agarose that had been prepared as previously described (15). Samples containing bovine cone or rod phosphodiesterase (see Methods) were similarly purified by immunoadsorption with ROS-1. The samples were incubated at $4^{\circ} \mathrm{C}$ for $2 \mathrm{~h}$ on a rotator, washed twice in $10 \mathrm{mM}$ Tris/ $\mathrm{HCl}$, $\mathrm{pH} 7.5,150 \mathrm{mM} \mathrm{NaCl}$ and once in $10 \mathrm{mM}$ Tris/HCl, $\mathrm{pH} \mathrm{7.5,} \mathrm{in} \mathrm{a}$ microfuge, and then eluted with $8 \mathrm{M}$ urea. Samples were electrophoresed in SDS on a $15 \%$ total acrylamide, $0.08 \%$ bisacrylamide gel as previously described $(14,15)$. The gel was blotted onto nitrocellulose at $30 \mathrm{~V}$ for $6 \mathrm{~h}$, blocked with $3 \%$ casein and probed with a monospecific antisera (Dr. Richard Lolley, Veterans Administration Hospital, Sepulveda, CA) directed to the bovine rod phosphodiesterase (33). The signal was developed using a Protoblot kit (Promega Biotec) as specified in the manufacturer's instructions. (Lane $A$ ) Detergent-solubilized tumor adsorbed with ethanolamine-blocked $\mathrm{CNBr}$-activated agarose (negative control). (Lane B) Detergent-solubilized tumor adsorbed with ROS-1-agarose. (Lane $C$ ) Bovine cone phosphodiesterase further purified with ROS-1-agarose. (Lane $D$ ) Bovine rod phosphodiesterase further purified with ROS-1-agarose.

reactions that result in the light-activated hydrolysis of the second messenger cGMP (37). The decrease in this cyclic nucleotide results in the closure of a cGMP-gated cation channel and the hyperpolarization of the cell (38). This biochemical process takes place exclusively in photoreceptors. This cell type has only been found in the retina and the pineal gland (39). No other tissue source of these enzymes has been observed $(30,40)$.

Two principal types of photoreceptors exist in the retina: the rod and the cone. In the human retina, the rod is the predominant photoreceptor and is present throughout the retina (41). The rod is more sensitive to light and is able to respond to a single photon $(42,43)$. Cones are responsible for 
Table I. Results of Screening Six Retinoblastomas and Five Cell Lines for Cone Outer Segment and CaM-dependent Phosphodiesterases

\begin{tabular}{|c|c|c|c|c|}
\hline \multirow[b]{2}{*}{ Tissue } & \multicolumn{2}{|c|}{ Antibody } & \multicolumn{2}{|c|}{ Activity recovered } \\
\hline & ROS-1 & $\mathrm{ACC}$ & Total & Percent \\
\hline \multicolumn{5}{|l|}{ Tumors } \\
\hline S.B. & 86 & 14 & 250 & 95 \\
\hline N.H. & 91 & 9 & 410 & 95 \\
\hline W.L. & 98 & $2^{*}$ & $>1,200$ & 95 \\
\hline C.T. & 40 & 60 & 150 & 90 \\
\hline N.N. & 50 & 50 & & $\ddagger$ \\
\hline M.M. & 99 & $<1$ & 75 & 75 \\
\hline \multicolumn{5}{|l|}{ Cell lines } \\
\hline RBLA 12 & 42 & 58 & 14 & 77 \\
\hline RBLA20 & $<5^{8}$ & $>95$ & 3 & 99 \\
\hline RBLA22 & 45 & 55 & 8 & 76 \\
\hline RBLA28 & 31 & 69 & 6 & 96 \\
\hline WERIII & $<5$ & $>95$ & 8 & 95 \\
\hline
\end{tabular}

Monoclonal antibody was coupled to Staphylococcal aureus as previously described (see Methods), incubated with aliquots of each fraction obtained from anion exchange HPLC profiles as described in Fig. 1, and the centrifuged supernatants were assayed for cGMP phosphodiesterase activity in the presence of $2 \mathrm{mg} / \mathrm{ml}$ histone using $10 \mu \mathrm{M}\left[{ }^{3} \mathrm{H}\right] \mathrm{cGMP}$ as substrate. The total activity left by each antibody was quantitated in each profile using a computer program based on the cubic spline integration function (55) and expressed as a percentage of the total activity in the profile. The total activity ( $\mathrm{nmol} / \mathrm{min} \times \mathrm{g}$ tissue) was similarly measured in the fractions of the HPLC profile after incubation with Staphylococcus aureus without antibody. ROS-1 is a monoclonal antibody that interacts exclusively with rod and cone outer segment CGMP phosphodiesterases $(15,24)$. ACC is a monoclonal antibody that interacts with CaM and with $\mathrm{CaM}$ bound to the calmodulin-dependent phosphodiesterases in the presence of calcium (27). The percentage recovery refers to the total activity recovered from the HPLC profile as compared to the total activity injected into the HPLC.

* A small peak of activity found after ROS-1 immunoadsorption and stimulation by calcium-CaM accounted for $\sim 2 \%$ of the activity in the profile.

${ }^{\ddagger}$ Because of enzyme instability during immunoadsorption, activity in this tumor was estimated to be of CaM-dependent or photoreceptor origin by comparing the percentage of activity in the HPLC profile activated in the presence of $\mathrm{CaM}$ to the total activity in the presence of histone.

A small peak of activity that could be stimulated by histone and immunoadsorbed by ROS-1 was detected in this profile and accounted for $<5 \%$ of the total activity thus suggesting the presence of the cone phosphodiesterase.

"WERI is a human retinoblastoma cell line established in 1974 from an effected 1-yr-old child with no family history of retinoblastoma (56) and was purchased from the American Type Culture Collection.

color vision (12) and are concentrated in a small central region of the retina called the fovea (41). Therefore, central, highacuity color vision is mediated by cones while peripheral, lowacuity vision is mediated by rods. Night vision is predominately mediated by rods.

Both rods and cones have similar but not identical cGMPmediated phototransduction cascades. The opsins and transducins in both photoreceptors share a high degree of amino
Table II. Presence of the Phototransduction Cascade in the RBLA22 Retinoblastoma Cell Line

\begin{tabular}{lc}
\hline \multicolumn{1}{c}{ Assay condition } & Activity \\
\hline EGTA (1 mM) & 1.4 \\
Calcium (0.5 mM)-CaM (110 nM) & 4.2 \\
GppNHp (50 $\mu \mathrm{M})$ & 9.0 \\
\hline
\end{tabular}

Cells were homogenized and phosphodiesterase assays were performed as described in Methods using $10 \mu \mathrm{M}\left[{ }^{3} \mathrm{H}\right] \mathrm{CGMP}$ as substrate in the presence of the indicated effectors. Activity is expressed as $\mathrm{nmol} / \mathrm{min} \times \mathrm{g}$ tissue. GppNHp is a nonhydrolyzable analogue of GTP.

acid identity but have been found to be distinct gene products $(12,13)$. Phosphodiesterases with different apparent subunit molecular masses have been found in cones and rods $(15,23)$. These two isozymes share a common antigenic epitope; however, they are clearly separable by anion exchange HPLC $(15,24)$.

At least three CaM-dependent phosphodiesterases have been purified and characterized, one from heart and two from brain $(27,44-46)$. These isozymes have subunit molecular masses of 59, 61, and $63 \mathrm{kD}$ respectively. These enzymes do not cross-react with the monoclonal antibody to the photoreceptor isozymes (ROS-1) but do react to an antibody to CaM (ACC) $(27,47)$. While CaM in the presence of calcium is necessary for the activation of the CaM-dependent phosphodiesterases, this activator has no effect on the photoreceptor isozymes (unpublished observation).

In this report, we have documented that the cone phosphodiesterase is functionally expressed in all six retinoblastomas and in three continuous cell lines tested. The specific activity of the phosphodiesterase was significantly higher in the tumor than in the cell lines suggesting that the expression of the phototransduction cascade may be reduced in cultured cells. In some of the cell lines, particularly those that have been in culture for long periods of time, the enzyme was not detected. The degree of apparent differentiation of the tumor as indicated by the presence of fleurettes or Flexner-Wintersteiner rosettes (1) did not correlate with the expression of the phosphodiesterase in agreement with previous analysis of retinoblastoma cell lines by northern blot with cone transducin and photopigment probes (26).

A recent histochemical study of well-differentiated retinoblastomas using anti-rhodopsin monoclonal antibodies demonstrated that four of the five tumors studied stained positively with two of five of the antibodies tested (48). The authors postulated that these well-differentiated tumors were of rod cell lineage. The results of our studies and others do not support this hypothesis. Past studies have shown that red-green photopigment mRNA but not rhodopsin mRNA was expressed in retinoblastoma (26). Furthermore, the observation that only two of the anti-rhodopsin antibodies recognized epitopes on the tumors while all five recognized epitopes on normal human retina suggests that the intact rhodopsin molecule may not be expressed in retinoblastoma. Further studies will be necessary to fully understand these discrepancies.

An argument could be made that our tumors contained microscopic amounts of normal retina that accounted for our phosphodiesterase profiles. Previous studies have shown that 
$50 \%$ of the total CGMP phosphodiesterase activity in the coneenriched human fovea and $>95 \%$ of the activity in the peripheral human retina is of rod origin (15). Therefore, the absence of the rod phosphodiesterase biochemically verifies the absence of normal retina in these studies.

The results showing the activation of the phototransduction cascade in the retinoblastoma cell line is intriguing. It is not currently believed that the photoreceptor contains all of the biochemical pathways necessary for photopigment recovery $(49,50)$ yet the data would suggest that enough photopigment remains associated with the opsin in the cells to allow transducin to exchange GDP for GTP and activate the phosphodiesterase. Several possible explanations could explain this finding. The biochemical pathways necessary for reinsertion of the photopigment into the opsin could all be present in the cells. Previous investigations have shown the presence of the interstitial retinol-binding protein in retinoblastoma (51). A recent observation suggests that the pathways necessary for photopigment recovery are different and perhaps more complete in the cone than the rod (52), the photoreceptor where most of the investigations in photopigment regeneration have occurred. Thermodynamics suggest that enough of the chromophore could be in the correct conformation in the serum used in the culture medium even in the absence of the enzymatic regenerative pathways. Because of the tremendous amplification potential of the phototransduction cascade, only catalytic amounts of opsin are necessary for initiation of these events. Although a previous report has suggested that the presence of the chromophore is necessary for opsin to activate the cascade (53), it is possible that the cone opsin does not need the chromophore to activate transducin. Finally, another receptor could replace the opsin. This last possibility is unlikely in that other receptors have not been shown to be effective activators of transducin (54) and the activating ligands for alternate receptors were not included in the assays.

The presence of the cone-specific phototransduction cascade in retinoblastoma suggests that this tumor has biochemically differentiated along the cone cell lineage. These findings permit the development of a unique model system to allow the study of cone phototransduction and of the individual components of the human cone phototransduction cascade. Conversely, further analysis of cone phototransduction may offer insight into the biology of retinoblastoma.

\section{Acknowledgments}

We thank Dr. Mary Hurwitz for her critical review of the manuscript.

This research was supported in part by grants from the National Institutes of Health (EY06656) and Retina Research Foundation. R. L. Hurwitz is the recipient of a Career Development Award from the American Cancer Society.

\section{References}

1. Tapley, N. D., L. C. Strong, and W. W. Sutow. 1984. Retinoblastoma. In Clinical Pediatric Oncology. W. W. Sutow, D. J. Fernbach, and T. J. Vietti, editors. C.V. Mosby Co., St. Louis, MD. 539-558.

2. Motegi, T. 1981. Lymphocyte chromosome survey in 42 patients with retinoblastoma: effort to detect 13q14 deletion mosaicism. Hum. Genet. 58:168.

3. Yunis, J. J., and N. Ramsey. 1978. Retinoblastoma and subband deletion of chromosome 13. Am. J. Dis. Child. 132:161-163.
4. Murphree, A. L., and W. F. Benedict. 1984. Retinoblastoma: clues to human oncogenesis. Science (Wash. DC). 223:1028-1033.

5. Godbout, R., T. P. Dryja, J. Squire, B. L. Gallie, and R. A. Phillips. 1983. Somatic inactivation of genes on chromosome 13 is a common event in retinoblastoma. Nature (Lond.). 304:451-453.

6. Cavenee, W. K., T. P. Dryja, R. A. Phillips, W. F. Benedict, R. Godbout, B. L. Gallie, A. L. Murphree, L. C. Strong, and R. L. White. 1983. Expression of recessive alleles by chromosomal mechanisms of retinoblastoma. Nature (Lond.). 305:779-784.

7. Dryja, T. P., W. K. Cavenee, R. L. White, J. M. Rapaport, R. Petersen, D. M. Albert, and G. A. P. Bruns. 1984. Homozygosity of chromosome 13 in retinoblastoma. N. Engl. J. Med. 310:550-553.

8. Friend, S. H., R. Bernards, S. Rogelj, R. A. Weinberg, J. M. Rapaport, D. M. Albert, and T. P. Dryja. 1986. A human DNA segment with properties of the gene that predisposes to retinoblastoma and osteosarcoma. Nature (Lond.). 323:643-646.

9. Fung, B. K.-K., J. B. Hurley, and L. Stryer. 1981. Flow of information in the light-triggered cyclic nucleotide cascade of vision. Proc. Natl. Acad. Sci. USA. 78:152-156.

10. Dratz, E. A., and P. A. Hargrave. 1983. The structure of rhodopsin and the rod outer segment disk membrane. Trends Biochem. Sci. 8:128-131.

11. Nathans, J., and D. S. Hogness. 1984. Isolation and nucleotide sequence of the gene encoding human rhodopsin. Proc. Natl. Acad. Sci. USA. 81:4851-4855.

12. Nathans, J., D. Thomas, and D. S. Hogness. 1986. Molecular genetics of human color vision; the genes encoding blue, green, and red pigments. Science (Wash. DC). 232:193-232.

13. Lerea, C. L., D. E. Somers, J. B. Hurley, I. B. Klock, and A. H. Bunt-Milam. 1986. Identification of specific transducin subunits in retinal rod and cone photoreceptors. Science (Wash. DC). 234:77-80.

14. Baehr, W., M. J. Devlin, and M. L. Applebury. 1979. Isolation and characterization of CGMP phosphodiesterase from bovine rod outer segments. J. Biol. Chem. 254:11669-11677.

15. Hurwitz, R. L., A. H. Bunt-Milam, M. L. Chang, and J. A. Beavo. 1985. cGMP Phosphodiesterase in rod and cone outer segments of the retina. J. Biol. Chem. 260:568-573.

16. Fesenko, E. E., S. S. Kolesnikov, and A. L. Lyubarsky. 1985. Induction by cGMP of cationic conductance in plasma membrane of retinal rod outer segment. Nature (Lond.). 313:310-313.

17. Cobbs, W. H., and E. N. Pugh, Jr. 1985. cGMP can increase rod outer-segment light-sensitive current 10 -fold without delay of excitation. Nature (Lond.). 313:585-587.

18. Yau, K.-W., and K. Nakatani. 1985. Light-induced reduction of cytoplasmic free calcium in retinal rod outer segment. Nature (Lond.). 313:579-582.

19. Haynes, L., and K.-W. Yau. 1985. Cyclic GMP-sensitive conductance in outer segment membrane of catfish cones. Nature (Lond.). 317:61-64.

20. Cobbs, W. H., A. E. Barkdoll, III, and E. N. Pugh, Jr. 1985. Cyclic GMP increases photocurrent and light sensitivity of retinal cones. Nature (Lond.). 317:64-66.

21. Cook, N. J., W. Hanke, and U. B. Kaupp. 1987. Identification, purification, and functional reconstitution of the cyclic GMP-dependent channel from rod photoreceptors. Proc. Natl. Acad. Sci. USA. 84:585-589.

22. Hurwitz, R. L., and J. A. Beavo. 1984. Immunotitration analysis of the rod outer segment phosphodiesterase. Adv. Cyclic Nucleotide Protein Phosphorylation Res. 17:239-248.

23. Gillespie, P. G., and J. A. Beavo. 1988. Characterization of a bovine cone phosphodiesterase purified by cyclic GMP-Sepharose chromatography. J. Biol. Chem. 263:8133-8141.

24. Hurwitz, R. L., A. H. Bunt-Milam, and J. A. Beavo. 1984. Characterization of the rod outer segment phosphodiesterase using monoclonal antibodies. J. Biol. Chem. 259:8612-8618.

25. Hurley, J. B., and L. Stryer. 1982. Purification and characterization of the gamma regulatory subunit of the cyclic GMP phospho- 
diesterase from retinal rod outer segments. J. Biol. Chem. 257:1109411099.

26. Bogenmann, E., M. A. Lochrie, and M. I. Simon. 1988. Cone cell-specific genes expressed in retinoblastoma. Science (Wash. DC). 240:76-78.

27. Hansen, R. S., and J. A. Beavo. 1986. Differential recognition of calmodulin-enzyme complexes by a conformation-specific anti-calmodulin monoclonal antibody. J. Biol. Chem. 261:14636-14645.

28. Putkey, J. A., G. R. Slaughter, and A. R. Means. 1985. Bacterial expression and characterization of proteins derived from the chicken calmodulin cDNA and a calmodulin processed gene. J. Biol. Chem. 260:4704-4712.

29. Bogenmann, E., and C. Mark. 1983. Routine growth and differentiation of primary retinoblastoma cells in culture. J. Natl. Cancer Inst. 70:95-99.

30. Lee, R. H., B. S. Lieberman, R. L. Hurwitz, and R. N. Lolley. 1985. Phosphodiesterase-probes show distinct defects in rd mice and Irish setter dog disorders. Invest. Ophthalmol. Vis. Sci. 26:1569-1579.

31. Miki, N., J. M. Baraban, J. J. Keirns, J. J. Boyce, and M. W. Bitensky. 1975. Purification and properties of the light-activated cyclic nucleotide phosphodiesterase of rod outer segments. J. Biol. Chem. 250:6320-6327.

32. Hansen, R. S., H. Charbonneau, and J. A. Beavo. 1988. Purification of calmodulin-stimulated cyclic nucleotide phosphodiesterase by monoclonal antibody affinity chromatography. Methods Enzymol. 159:543-556.

33. Lee, R. H., S. E. Navon, B. M. Brown, B. K.-K. Fung, and R. N. Lolley. 1988. Characterization of a phosphodiesterase-immunoreactive polypeptide from rod photoreceptors of developing $r d$ mouse retinas. Invest. Ophthalmol. Vis. Sci. 29:1021-1027.

34. Hurwitz, R. L., K. Hirsch, D. J. Clark, V. N. Holcombe, and M. Y. Hurwitz. 1990. Induction of a calcium calmodulin-dependent phosphodiesterase during pHA-stimulated lymphocyte mitogenesis. $J$. Biol. Chem. In press.

35. Klee, C. B., T. H. Crouch, and M. H. Krinks. 1979. Subunit structure and catalytic properties of bovine brain calcium-dependent cyclic nucleotide phosphodiesterase. Biochemistry. 18:722-729.

36. Yamanaka, G., F. Eckstein, and L. Stryer. 1985. Stereochemistry of the guanyl nucleotide binding site of transducin probed by phosphorothioate analogues of GTP and GDP. Biochemistry. 24:8094-8101.

37. Stryer, L. 1986. Cyclic GMP cascade of vision. Annu. Rev. Neurosci. 9:87-98.

38. Yau, K.-W., and D. A. Baylor. 1989. Cyclic GMP-Activated Conductance of Retinal Photoreceptor Cells. Annu. Rev. Neurosci. 12:289-327.

39. Zimmerman, B. L., and M. O. M. Tso. 1975. Morphologic evidence of photoreceptor differentiation of pinealocytes in the neonatal rat. J. Cell Biol. 66:60-75.

40. Van Veen, T., T. Ostholm, P. Gierschik, A. M. Spiegel, R. Somers, H. W. Korf, and D. C. Klein. 1986. Alpha-transducin immunoreactivity in retinae and sensory pineal organs of adult vertebrates. Proc. Natl. Acad. Sci. USA. 83:912-916.

41. Hogan, M. J., J. A. Alvarado, and J. E. Weddell. 1971. Histology of the Human Eye. W.B. Saunders Co., Philadelphia, PA. 424-441.
42. Baylor, D. A., T. D. Lamb, and K.-W. Yau. 1979. Responses of retinal rods to single photons. J. Physiol. (Lond.). 288:613-634.

43. Baylor, D. A. 1987. Photoreceptor signals and vision. Invest. Ophthalmol. Vis. Sci. 28:34-49.

44. Hansen, R. S., and J. A. Beavo. 1982. Purification of two calcium/calmodulin-dependent forms of cyclic nucleotide phosphodiesterase by using conformation-specific monoclonal antibody chromatography. Proc. Natl. Acad. Sci. USA. 79:2788-2792.

45. Sharma, R. K., T. H. Wang, E. Wirch, and J. H. Wang. 1980. Purification and properties of bovine brain calmodulin-dependent cyclic nucleotide phosphodiesterase. J. Biol. Chem. 255:5916-5923.

46. Sharma, R. K., A-M. Adachi, A. Kazuo, and J. H. Wang. 1984. Demonstration of bovine brain calmodulin-dependent cyclic nucleotide phosphodiesterase isozymes by monoclonal antibodies. J. Biol. Chem. 259:9248-9254.

47. Hurwitz, R. L., R. S. Hansen, S. A. Harrison, T. J. Martins, M. C. Mumby, and J. A. Beavo. 1984. Immunologic approaches to the study of cyclic nucleotide phosphodiesterase. Adv. Cyclic Nucleotide Protein Phosphorylation Res. 16:89-106.

48. Vrabec, T., V. Arbizo, G. Adamus, J. H. McDowell, P. A. Hargrave, and L. A. Donoso. 1989. Rod cell-specific antigens in retinoblastoma. Arch. Ophthalmol. 107:1061-1063.

49. Bridges, C. D. B., S-L. Fong, G. I. Liou, R. Alvarez, and R. A. Landers. 1983. Transport, utilization and metabolism of visual cycle retinoids in the retina and pigment epithelium. In Progress in Retinal Research. N. N. Osborne and G. J. Chader, editors. Pergamon Press, Ltd., Oxford. 137-162.

50. Chader, G. J., B. Wiggert, Y-L. Lai, L. Lee, and R. T. Fletcher. 1983. Interphotoreceptor retinol-binding protein: a possible role in retinoid transport to the retina. In Progress in Retinal Research. N. N. Osborne and G. J. Chader, editors. Pergamon Press, Ltd., Oxford. 163-189.

51. Bridges, C. D. B., S-L. Fong, R. A. Landers, G. I. Liou, and R. L. Font. 1985. Interstitial retinol-binding protein (IRBP) in retinoblastoma. Neurochem. Int. 7:875-881.

52. Jones, G. J., R. K. Crouch, B. Wiggert, M. C. Cornwall, and G. J. Chader. 1989. Retinoid requirements for recovery of sensitivity after visual-pigment bleaching in isolated photoreceptors. Proc. Natl. Acad. Sci. USA. 86:9606-9610.

53. Fung, B. K.-K. 1987. Transducin: structure, function and role in phototransduction. In Progress in Retinal Research. N. N. Osborne and G. J. Chader, editors. Pergamon Press, Ltd., Oxford. 151-177.

54. Cerione, R. A., C. Staniszewski, J. L. Benovic, R. J. Lefkowitz, M. G. Caron, P. Gierschik, R. Somers, A. M. Spiegel, J. Codina, and L. Birnbaumer. 1985. Specificity of the functional interactions of the beta-adrenergic receptor and rhodopsin with guanine nucleotide regulatory proteins reconstituted in phospholipid vesicles. J. Biol. Chem. 260:1493-1500.

55. Forsythe, G., M. Malcolm, and C. Moler. 1977. Computer Methods for Mathematical Computations. Prentice Hall, Englewood Cliffs, NJ. 70-79.

56. McFall, R. C., T. W. Sery, and M. Makadon. 1977. Characterization of a new continuous cell line derived from a human retinoblastoma. Cancer Res. 37:1003-1010. 